\title{
Stimulation of $\mathrm{Cl}^{-}$secretion by the mucoactive drug S-carboxymethylcysteine-lysine salt in the isolated rabbit trachea
}

\author{
B. Colombo*, P. Turconi*, L. Daffonchio**, G. Fedele**, C. Omini**, D. Cremaschi*
}

Stimulation of $\mathrm{Cl}$-secretion by the mucoactive drug $S$-carboxymethylcysteine-lysine salt in the isolated rabbit trachea. B. Colombo, P. Turconi, L. Daffonchio, G. Fedele, C. Omini, D. Cremaschi. CERS Journals Ltd 1994.

ABSTRACT: Ion transport by the airway epithelium contributes to the regulation of the quantity and composition of respiratory tract fluid, thereby affecting mucociliary clearance. We have investigated the effect of the mucoactive drug S-carboxymethylcysteine-lysine salt (S-CMC-Lys) on the transepithelial bioelectric properties of isolated rabbit trachea.

Transepithelial potential difference (Vms), short-circuit current (Isc) and resistance $(R)$ were measured in the isolated rabbit trachea mounted between flux halfchambers, in the presence and in the absence of S-CMC-Lys $(100 \mu M)$, added to the mucosal or submucosal chamber. In some experiments, tissues were also exposed to ion channel-inhibitors, in order to evaluate the contribution of $\mathrm{Na}^{+}$and $\mathrm{Cl}^{-}$active transport to Isc.

The excised rabbit trachea expressed transepithelial bioelectric properties based on an active ion transport supported by the $\mathrm{Na}^{+}-\mathrm{K}^{+}$-adenosine triphosphatase (ATPase) activity, since ouabain $(500 \mu \mathrm{M})$ completely abolished the transepithelial potential difference. In control preparations, Vms and Isc declined significantly during 300 min recording, whereas $\mathrm{R}$ remained constant. The Isc decline was essentially attributable to a decrease in $\mathrm{Cl}^{-}$transport. Bumetanide $(100 \mu \mathrm{M})$ almost completely abolished the Isc fraction related to $\mathrm{Cl}^{-}$transport. Treatment of the tissues with S-CMC-Lys reduced the progressive fall in Isc, with the most clear-cut and significant effect observed for the mucosal treatment. In parallel, S-CMC-Lys significantly lowered R, without affecting Vms. Either mucosal or submucosal exposure to S-CMC-Lys significantly increased $\mathrm{Cl}^{-}$secretion to normal values, whilst $\mathrm{Na}^{+}$ absorption was not modified. The ability of S-CMC-Lys to restore $\mathrm{Cl}^{-}$transport was, however, lost in bumetanide treated tissues.

These data demonstrate the ability of S-CMC-Lys to modulate active ion transport across an airway epithelium, an effect which may contribute to its mucoregulatory activity.

Eur Respir J., 1994, 7, 1622-1628.
*General Physiology and Biochemistry Dept, University of Milan, Italy. **Pharmacological Dept, Dompe' farmaceutici S.p.A, Milan, Italy.

Correspondence: L. Daffonchio Dompe' farmaceutici S.p.A.

via S. Martino 12

20122 Milan

Italy

Keywords: Airway epithelium

$\mathrm{Cl}^{-}$secretion

mucus regulation

rabbit trachea

S-carboxymethylcysteine-lysine salt transepithelial bioelectric properties

Received: March 161993

Accepted after revision April 171994
Secretion and/or absorption of ions across airway epithelia represent an important driving force, which regulates the volume and composition of airway surface liquid. This fluid movement, in turn, determines the water content of the airway mucus layer, thereby affecting the efficiency of mucociliary clearance [1].

Active transport of ions through the airway epithelium generates a transepithelial potential difference, which can be measured with in vivo and in vitro techniques. Canine trachea has been widely used as a model to study airway epithelial ion transport in vitro [2-4], although in this species submucosal glands within the airways probably contribute to net electrolyte and water flow across the epithelial barrier. In contrast to canine trachea, rabbit tracheal mucosa is composed almost entirely of superficial epithelial cells with few submucosal glands [5]. Therefore, active ion transport and the derived elec- trical properties of the airway epithelium have also been investigated in rabbit excised trachea $[6,7]$, taken as an alternative experimental model where ion flux depends mainly on processes in the superficial epithelial cells.

$\mathrm{S}$-carboxymethylcysteine-lysine salt (S-CMC-Lys) is a mucoactive drug used in the therapy of lung diseases characterized by impaired mucus clearance, such as asthma and chronic bronchitis [8,9]; normalization of mucus secretion provided by this compound seems to depend on its ability to restore the correct balance between sialoand fuco-mucins, thereby increasing mucus fluidity and removal [10]. On the other hand, little is known about the possible additive effect on other processes involved in the regulation of mucus composition and its water content.

The aim of this study was to investigate a possible interference of S-CMC-Lys on active ion transport across 
an airway epithelium. In particular, we verified the effect of this drug on the bioelectric properties of rabbit tracheal epithelium, using the classical Ussing chamber technique.

\section{Methods}

\section{General}

Male New Zealand white rabbits, weight range 2.8-3.3 $\mathrm{kg}$ were killed by cervical dislocation, the thorax opened and the trachea removed. The excised trachea was placed in oxygenated $\left(\mathrm{O}_{2} / \mathrm{CO}_{2}: 95 / 5 \%\right)$ Krebs solution (composition in $\mathrm{mM}$ : $142.9 \mathrm{Na}^{+} 5.9 \mathrm{~K}^{+}, 2.5 \mathrm{Ca}^{2+}, 1.2 \mathrm{Mg}^{2+}, 127.7$ $\mathrm{Cl}^{-}, 24.9 \mathrm{HCO}_{3}^{-}, 1.2 \mathrm{SO}_{4}^{2-}, 1.2 \mathrm{H}_{2} \mathrm{PO}_{4}^{-}, 5.5$ glucose), and dissected free of connective and adipose tissues. One segment close to the bronchial bifurcation was cut, opened along the posterior side and mounted as a sheet between flux half-chambers (Ussing chamber) with an aperture of $1.40 \mathrm{~cm}^{2}$. Both submucosal and mucosal surfaces were bathed with $5 \mathrm{ml}$ of oxygenated Krebs solution maintained at $30^{\circ} \mathrm{C}$. This temperature was chosen in order to slow deterioration of the tissues during the long study period. Once the tissue was set up in the Ussing chamber, the recording of bioelectric variables was started (time 0).

Transepithelial electric potential difference (Vms, $\mathrm{mV}$ ) was measured by calomel-half cells connected by agar $(4 \%)-\mathrm{KCl}(0.5 \mathrm{M})$ bridges to the incubation medium. Short-circuit current (Isc, $\mu \mathrm{A} \cdot \mathrm{cm}^{-2}$ ) was measured by $\mathrm{Ag} / \mathrm{AgCl}$ electrodes, dipped in a Krebs solution and connected through agar-Krebs solution bridges to the incubation medium. Tissues were studied under open-circuit conditions with intermittent (every $10 \mathrm{~min}$ ) short circuiting (max $10 \mathrm{~s}$ ). During the ion transport analysis with inhibitors, short-circuiting was performed every min for the first 5 min after the addition of the channel-blockers, and subsequently at $5 \mathrm{~min}$ intervals. Vms and Isc were recorded immediately before and on clamping, respectivly. Both determinations were performed with an automatic device (S. Henin, Milan, Italy), which allowed automatic subtraction of the bathing fluid resistance for a correct measurement of Isc, and recorded with a double pen chart recorder (PM8262, Philips, Eindhoven, The Netherlands). Tissue resistance $\left(\mathrm{R}, \mathrm{Ohm} \cdot \mathrm{cm}^{2}\right)$ was calculated from the ratio between $\mathrm{Vms}$ and Isc.

In order to avoid an increase in solute concentration due to evaporation, the bathing solution in the chambers was replaced after the first $40 \mathrm{~min}$, and thereafter every 60 min throughout the experiment, with Krebs solution only (control tissues) or with Krebs solution containing the different drugs, according to the protocol design.

\section{Pharmacological treatments}

In four preliminary experiments, $150 \mathrm{~min}$ after the beginning of the experiment, the Krebs solution in the submucosal chamber was replaced with the same solution containing $500 \mu \mathrm{M}$ ouabain, a $\mathrm{Na}^{+}-\mathrm{K}^{+}$- adenosine triphosphatase inhibitor.

In the following experiments, at $40 \mathrm{~min}$ and at each subsequent medium change, the bathing solution in the submucosal or mucosal chamber was replaced with Krebs solution containing $100 \mu \mathrm{M}$ S-CMC-Lys. In other tissues, either control or S-CMC-Lys (mucosal) treated, the $\mathrm{Cl}^{-}$-cation co-transport inhibitor bumetanide $(100 \mu \mathrm{M})$ [11] was also present at the submucosal side from the 60th min (fig. 1). a)
Mucosal Krebs

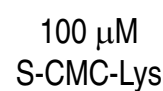

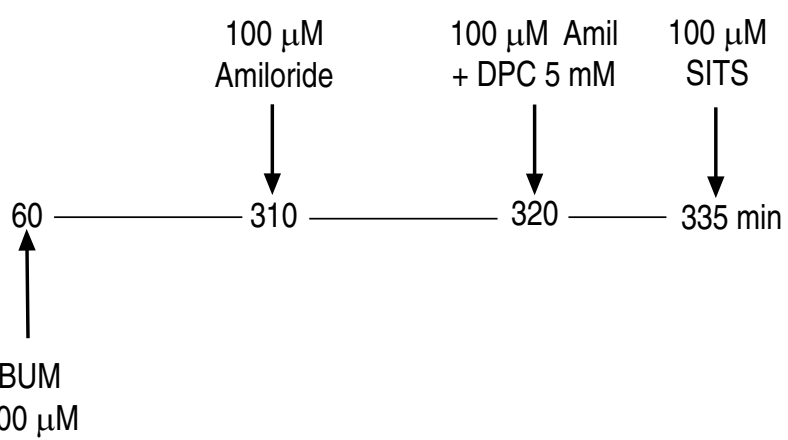
Mucosal
Krebs

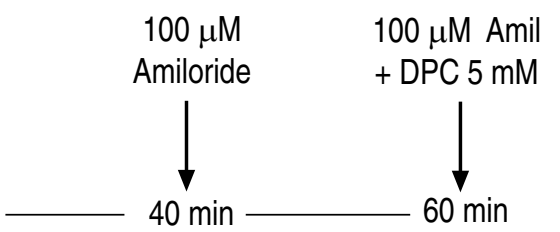
Krebs

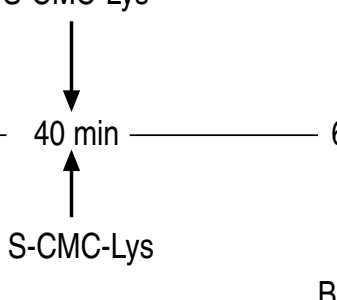

$100 \mu \mathrm{M}$

\section{Submucosal Krebs}

Fig. 1. - Time course of experimental procedure a) analysis started at $310 \mathrm{~min}$ (control or S-CMC-Lys treated tracheas b) analysis started at 40 min (control preparation only): S-carboxymethylcysteine-lysine salt; BUM: bumetanide; Amil: amilorido; DPC: diphenylamine-2-carboxylate; SITS: 4-acetamido-4'-isothiocyanatostilbene-2,2'-disulphonic acid. 


\section{Analysis of ion transport}

An analysis of ion transport was performed in some experiments, in order to evaluate the contribution of $\mathrm{Na}^{+}$ and $\mathrm{Cl}^{-}$transport to Isc. In particular, it was done by replacing the mucosal medium with Krebs solution containing amiloride $100 \mu \mathrm{M}, \mathrm{a} \mathrm{Na}^{+}$channel-blocker [12]. Ten min later, Krebs containing amiloride plus diphenylamine-2-carboxylate (DPC) $5 \mathrm{mM}, \mathrm{a} \mathrm{Cl}^{-}$channel-inhibitor [13], was again replaced in the mucosal chamber and the electric variables followed for additional $15 \mathrm{~min}$. In some tissues, Krebs containing amiloride plus DPC plus 4-acetamido-4'-isothiocyanatostilbene-2,2'-disulphonic acid (SITS) $100 \mu \mathrm{M}$ was then replaced in the mucosal chamber and variables measured for $10 \mathrm{~min}$ (fig. 1).

The analysis of ion transport was started in separate control preparations 40 and $310 \mathrm{~min}$ from the beginning of the experiment, whereas in S-CMC-Lys and/or bumetanide treated tissues it was started at $310 \mathrm{~min}$. In S-CMC-Lys and/or bumetanide treated tracheas, the drugs were present at the mucosal or submucosal side also throughout the ion transport analysis.

\section{Statistical analysis}

Data are reported as mean \pm SEM from $\mathrm{n}$ replications. Only one tracheal segment from each animal was used in each experiment (one replication). The three variables measured were expressed either as absolute values or as percentage decrease from basal values; in the latter case, values measured at $40 \mathrm{~min}$ from the beginning of the experiment were taken as basal, since at this time the bioelectric variables were generally steady. The basal absolute values for $\mathrm{Vms}$, Isc and $\mathrm{R}$ were not statistically different among the groups considered. Since in some tissues the decrease in Isc induced by amiloride tended to recover, the \% Isc attributable to $\mathrm{Na}^{+}$transport was referred to as the peak \% decrease in Isc induced by the $\mathrm{Na}^{+}$channel-blocker. Consequently, the \% Isc attributable to $\mathrm{Cl}^{-}$movement was referred to as the further \% decrease in Isc due to DPC treatment, calculated from amiloride peak effect.

The time-course profile for percentage decrease in $\mathrm{Vms}$, Isc and $\mathrm{R}$ were compared by means of the analysis of variance according to a split-plot model [14], which allows evaluation of the overall interaction treatment $x$ time. A Student's t-test for unpaired data was used to compare between treatments the changes in tracheal bioelectric variables at specific time-points and those due to amiloride and DPC. Comparison of results within treatments were statistically assessed by Student's $\mathrm{t}$-test for paired data. A probability level of $\mathrm{p}<0.05$ (twotailed) was considered statistically significant.

\section{Drugs used}

Ouabain, bumetanide and amiloride were purchased from Sigma; DPC was purchased from Aldrich-Chemie; S-CMC-Lys was obtained from Dompe' farmaceutici S.p.A.
Table 1. - Transepithelial potential difference (Vms), short-circuit current (Isc) and resistance (R) measured in control isolated rabbit tracheas at basal time (40 $\mathrm{min})$ and at $300 \mathrm{~min}$ from the beginning of the experiment

\begin{tabular}{lrrr}
\hline Variable & \multicolumn{1}{c}{ Basal } & \multicolumn{1}{c}{$300 \mathrm{~min}$} & \% decrease \\
\hline $\mathrm{Vms} \mathrm{mV}$ & $12.3 \pm 0.8$ & $9.4 \pm 0.7^{*}$ & $23.3 \pm 1.5$ \\
$\mathrm{Isc} \mu \mathrm{A} \cdot \mathrm{cm}^{-2}$ & $123.6 \pm 5.8$ & $96.6 \pm 3.4^{*}$ & $19.7 \pm 2.1$ \\
$\mathrm{R} \mathrm{Ohm} \cdot \mathrm{cm}^{2}$ & $98.5 \pm 4.4$ & $96.9 \pm 5.9$ & $2.9 \pm 2.5$ \\
\hline
\end{tabular}

Results are shown as absolute values and percentage decrease during 300 min recording. Data represents the mean \pm SEM from 40 replications. *: significantly different from basal (Student's t-test for paired data).
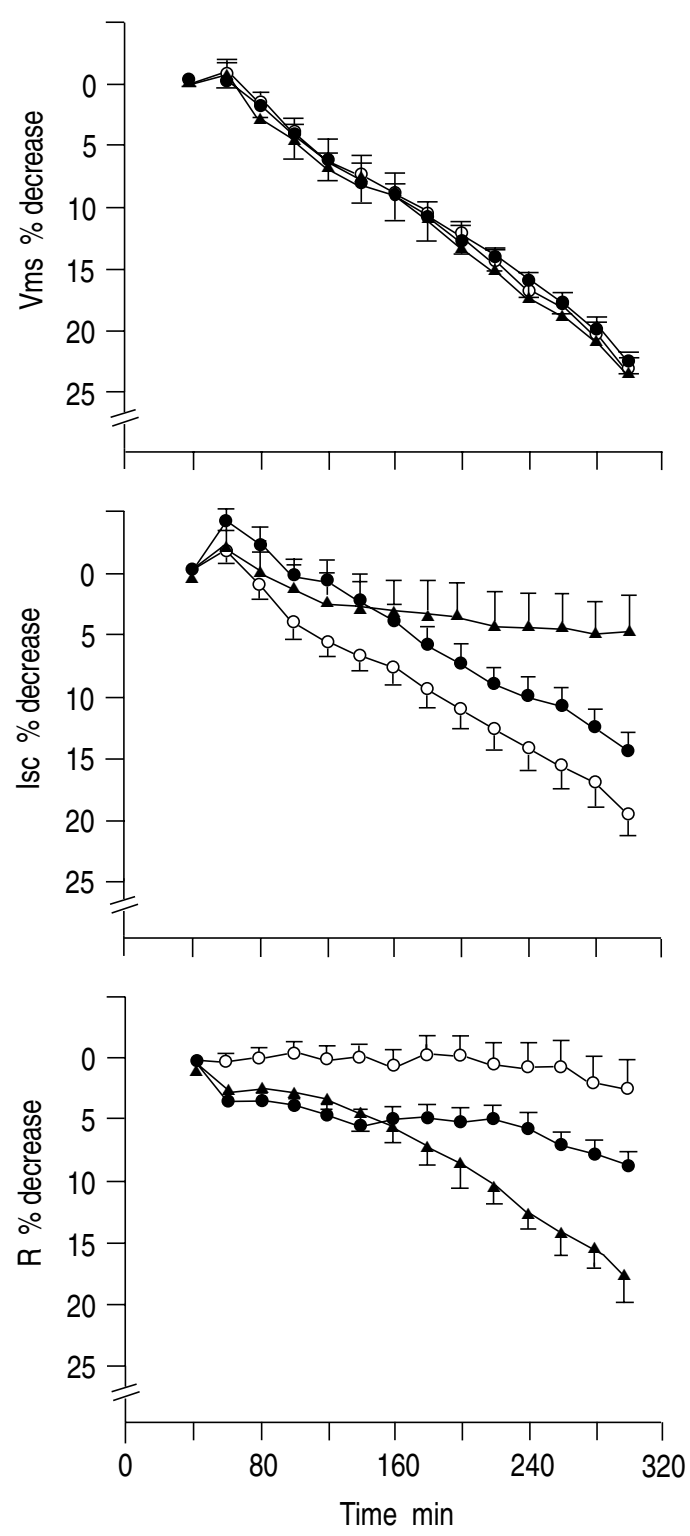

Fig. 2. - Time-course for the percentage change in transepithelial potential difference (Vms), short-circuit current (Isc) and resistance (R) in isolated rabbit tracheas. The bioelectric variables were measured in control preparation ( $O$; $n=40$ ), and tissues treated with $S$ carboxymethlcysteine-lysine salt (S-CMC-Lys) $(100 \mu \mathrm{M})$ from the mucosal ( $\boldsymbol{\Delta} ; \mathrm{n}=38)$ or submucosal $(\boldsymbol{\bullet} ; \mathrm{n}=44)$ side. Each point represent the mean \pm SEM from $n$ replications. The interaction treatment $\times$ time was statistically significant for the percentage decrease in both Isc and R (analysis of variance, split-plot model). 


\section{Results}

\section{Effect of oubain}

In a first series of experiments, the methodological approach was characterized and validated. In particular, preliminary experiments revealed that the intact rabbit trachea (epithelium + cartilage) can develop a Vms (lumen negative) and Isc, though a progressive decrease (about $18 \%$ ) in Vms and Isc values was observed over $150 \mathrm{~min}$. When ouabain $500 \mu \mathrm{M}$ was added to the submucosal chamber, a marked fall in tissue bioelectric function was observed, with Vms and Isc values dropping almost to zero within $60 \mathrm{~min}(0.3 \pm 0.1 \mathrm{mV}, 4.6+1.4$ $\mu \mathrm{A} \cdot \mathrm{cm}^{-2}$, respectively; $\left.\mathrm{n}=4\right)$.

\section{Effect of S-CMC-Lys on bioelectric properties}

In a second series of experiments, the time-course of the electric variables was followed up to $300 \mathrm{~min}$, in control and S-CMC-Lys treated tissues. In control preparations, Vms and Isc fell significantly with time, decreasing approximetely $20 \%$ over 300 min for varables; at this time, $\mathrm{R}$ was not significantly changed (table 1 and fig. 2). Treatment of rabbit tracheas with S-CMCLys resulted in an overall protection from the progressive loss in active ion transport, with the clearest effect seen after mucosal treatment (fig. 2). In particular, whilst the time-course of Vms was similar in control (\% decrease at $300 \min 23.3 \pm 1.5 ; \mathrm{n}=40)$ and treated tissues $(\%$ decrease at $300 \mathrm{~min} 24.0 \pm 1.7$ and $22.6 \pm 1.4$ after mucosal $(n=38)$ and submucosal $(n=44)$ treatment, respectively), S-CMC-Lys significantly reduced the overall profile of Isc fall during time (fig. 2), the interaction treatment $\times$ time for this variable being significant. The percentage decrease in Isc calculated at $300 \mathrm{~min}$ was $19.7 \pm 2.1$ $(n=40), 4.8 \pm 2.8(n=38)$ and $14.7 \pm 1.6(n=44)$ in control tissues, after mucosal treatment and after submucosal treatment, respectively.

Specific comparison for values at $300 \mathrm{~min}$ revealed that the percentage fall in Isc observed in tracheas exposed to S-CMC-Lys from the mucosal side, but not the submucosal, was significantly lower as compared to controls. On the other hand, the ability of S-CMC-Lys to prevent the progressive fall in Isc was completely lost in tissues treated with bumetanide (table 2). S-CMCLys treatment also significantly affected the time-course of $\mathrm{R}$, which was reduced by the mucoactive drug over 300 min recording (fig. 2), with a significant interaction treatment $\times$ time. In particular, the percentage reduction in $\mathrm{R}$ calculated at $300 \mathrm{~min}$ in tissues exposed to S-CMCLys from the mucosal or submucosal side (18.6 \pm 2.0 , $\mathrm{n}=38 ; 8.9 \pm 1.3, \mathrm{n}=44$, respectively) was significantly greater than that observed in control preparations $(2.8 \pm 2.5$, $\mathrm{n}=40$ ).

\section{Ion transport and bioelectric properties}

Amiloride and DPC caused a significant decrease in Isc, paralleled by a concomitant and significant increase in R. Figure 3 shows the profile of Isc fall and R increase after amiloride and DPC addition in control preparations when the ion transport analysis was started 40 min from the beginning of the experiment. The analysis of $\mathrm{Na}^{+}$ and $\mathrm{Cl}^{-}$transports also revealed that the two ions accounted for a different degree to Isc, according to the experimental conditions. The results are summarized in table 2. In control preparations (analysis started at $40 \mathrm{~min}$ ) the \% Isc attributable to $\mathrm{Cl}^{-}$secretion (DPC-inhibited fraction of Isc) was significantly higher than that accounted for by $\mathrm{Na}^{+}$absorption (amiloride-inhibited fraction of Isc). A small residual current was also observed, of which only a negligible proportion could be attributed

Table 2. - Effect of S-carboxymethylcysteine-lysine salt (S-CMC-Lys) on the percentage short-circuit current (Isc) attributable to $\mathrm{Na}^{+}$and $\mathrm{Cl}^{-}$active transport in isolated rabbit tracheas

\begin{tabular}{|c|c|c|c|c|c|c|}
\hline Treatment & $\begin{array}{l}\text { Start time } \\
\text { analyses } \min \end{array}$ & $\mathrm{n}$ & $\% 300 \min$ & $\% \mathrm{Na}^{+}$ & $\% \mathrm{Cl}^{-}$ & \%residual \\
\hline Control & 40 & 12 & - & $38.4 \pm 3.6$ & $55.4 \pm 3.1 * \S$ & $6.6 \pm 0.8$ \\
\hline Control & 310 & 19 & $17.3 \pm 2.6$ & $33.8 \pm 2.3$ & $41.8 \pm 2.3$ & $7.1 \pm 1.0$ \\
\hline S-CMC-Lys M & 310 & 24 & $3.5 \pm 3.5^{\S}$ & $39.3 \pm 2.3$ & $51.8 \pm 3.7 * \S$ & $5.3 \pm 0.8$ \\
\hline S-CMC-Lys S & 310 & 21 & $13.0 \pm 1.9$ & $30.7 \pm 2.3$ & $50.2 \pm 2.6 * \S$ & $6.0 \pm 0.8$ \\
\hline BUM & 310 & 6 & $31.5 \pm 5.0^{\S}$ & $54.8 \pm 2.7 \S$ & $10.1 \pm 1.8 * \S$ & $3.6 \pm 1.4$ \\
\hline S-CMC-Lys M + BUM & 310 & 6 & $37.1 \pm 3.8^{\dagger}$ & $48.5 \pm 3.7^{\dagger}$ & $11.5 \pm 1.7 * \dagger$ & $2.5 \pm 1.2^{\dagger}$ \\
\hline
\end{tabular}

Results are shown as \% of Isc attributable to spontaneous decrease during $300 \mathrm{~min}$ recording ( $\% 300 \mathrm{~min}$ ), decrease due to blockade of $\mathrm{Na}^{+}\left(\% \mathrm{Na}^{+}\right.$; amiloride $\left.100 \mu \mathrm{M}\right)$ and $\mathrm{Cl}^{-}\left(\% \mathrm{Cl}^{-}\right.$; amiloride+DPC $\left.5 \mathrm{mM}\right)$ channels, and residual Isc. Values measured $40 \mathrm{~min}$ from the beginning of the experiments were taken as basal=100\% in all the groups. Note that $40 \mathrm{~min}$ and $310 \mathrm{~min}$ refer to the time at which the ion transport analysis was started. S-CMC-Lys $(100 \mu \mathrm{M})$ was present at the mucosal (M) and submucosal (S) side of the tissue $40 \mathrm{~min}$ after the beginning of the experiment. Bumetanide (BUM, $100 \mu \mathrm{M})$ was present at the submucosal side $60 \mathrm{~min}$ after the beginning of the experiment (see fig. 1). Data represent the mean \pm SEM from $\mathrm{n}$ replications. *Significantly different from $\% \mathrm{Na}^{+}$(Student's t-test for paired data); $\$$ : significantly different from control 310 min (Student's ttest for unpaired data); $\dagger$ : not significantly different from BUM 310 min (Student's t-test for unpaired data). 

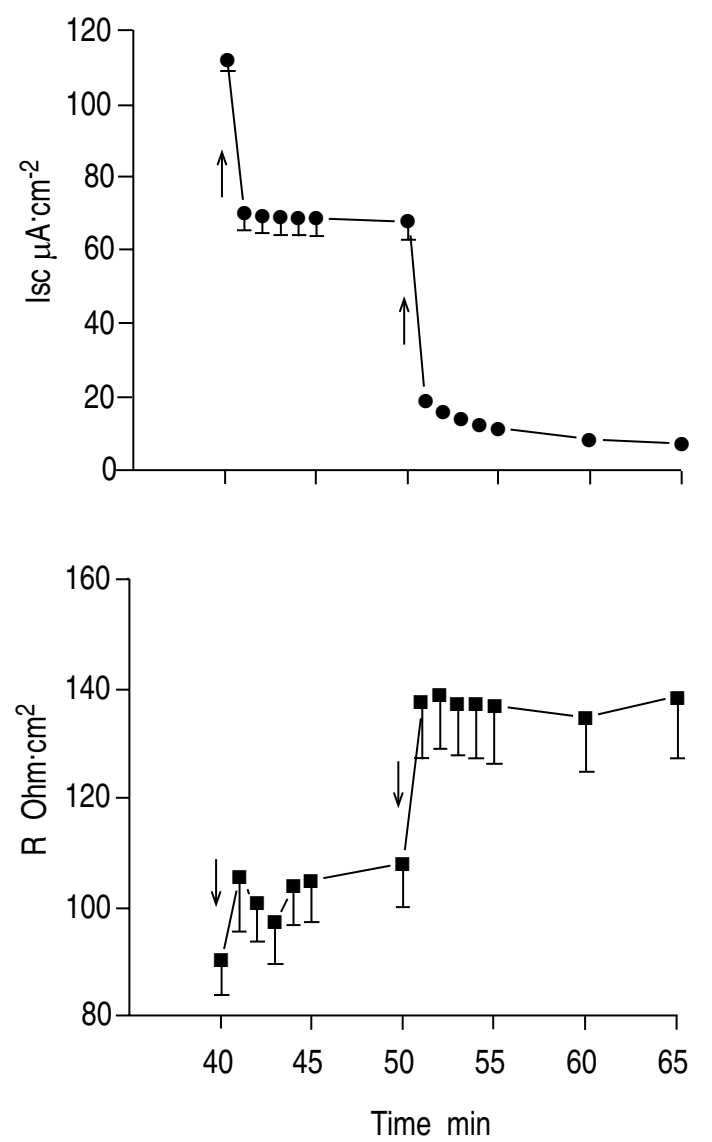

Fig. 3. - Profile of short-circuit current (Isc) and resistance (R) changes in control isolated rabbit tracheas after the addition of 100 $\mu \mathrm{M}$ amiloride (first arrow) and amiloride $+5 \mathrm{mM}$ diphenylamine-2-carboxylate (DPC) (second arrow) to the mucosal side of the tissue. The ion transport analysis was started $40 \mathrm{~min}$ after the beginning of the experiment. Each point represents the mean \pm SEM from 12 replications.

to $\mathrm{Cl}^{-}$transport through SITS-sensitive channels (percentage decrease in Isc due to SITS addition 2.0 \pm 0.5 , $\mathrm{n}=12$ ). When the ion analysis was performed in control tracheas $310 \mathrm{~min}$ from the beginning of the experiment, a significant decrease in $\mathrm{Cl}^{-}$secretion through DPC-sensitive channels was observed, as compared to the $40 \mathrm{~min}$ condition, with no change in $\mathrm{Na}^{+}$transport. Treatment of the tissues with bumetanide increased the \% Isc attributable to $\mathrm{Na}^{+}$transport and markedly reduced the percentage decrease in Isc due to DPC addition.

\section{Effect of S-CMC-Lys on ion transport}

Mucosal and submucosal treatment with S-CMC-Lys resulted in a significant increase in the \% Isc attributable to $\mathrm{Cl}^{-}$secretion (DPC-inhibited fraction of Isc), as compared to the corresponding controls (ion transport analysis started at $310 \mathrm{~min}$ ) (table 2). In particular, SCMC-Lys affected $\mathrm{Cl}^{-}$secretion only through DPC-inhibited apical channels, without interference on $\mathrm{Cl}^{-}$secretion through SITS-inhibited channels; the \% Isc attributable to $\mathrm{Cl}^{-}$active movement through the latter pathway was $2.0 \pm 0.6(n=10), 1.1 \pm 0.2(n=24)$ and $1.1 \pm 0.3(n=21)$ in control tissues, after mucosal treatment and after sub- mucosal treatment, respectively. On the other hand, SCMC-Lys did not modify either the percentage reduction in Isc due to amiloride exposure and the residual \% Isc (table 2). As a result, in tissues treated with the mucoactive drug, the \% Isc accounted for by $\mathrm{Cl}^{-}$secretion again significantly exceeded that attributable to $\mathrm{Na}^{+}$ absorption, as was observed for control tissues at $40 \mathrm{~min}$. In tissues treated with bumetanide, the fraction of Isc inhibited by either amiloride or DPC was not modified by mucosal treatment with S-CMC-Lys (table 2).

\section{Discussion}

Active absorption and/or secretion of ions across an airway epithelium, generating transepithelial Vms and Isc, and the derived passive diffusion of water, are important processes in the regulation of mucociliary clearance, in that they contribute to the modulation of water content in the mucus sol layer [1, 15-17].

In excised rabbit trachea (epithelium + cartilage), a transepithelial potential difference could be measured, which was accounted for by an active ion transport supported by $\mathrm{Na}^{+}-\mathrm{K}^{+}$- adenosine triphosphatase (ATPase) activity. In fact, addition to the submucosal side of the classical $\mathrm{Na}^{+}-\mathrm{K}^{+}$-ATPase inhibitor, ouabain, completely abolished the transepithelial potential difference and shortcircuit current, showing that active sites in the epithelium could be reached by drug applied to the submucosal side of the trachea, despite the presence of the cartilage.

In our experiments, a progressive fall in $\mathrm{Vms}$ and Isc was observed over time, while $\mathrm{R}$ remained constant. Similar results have already been reported by JARNIGAN et al. [7] in the same experimental model; according to these authors, the rate of decline in electric variables could not be influenced by modifying the protocol of tissue preparation or by exposing the tissue to either more complete bathing media or to diluted rabbit plasma. In this regard, since Isc fell but $\mathrm{R}$ did not, it is possible to speculate that a decline in activity of the basolateral $\mathrm{Cl}^{-}$ -cation co-transport and/or $\mathrm{Na}^{+}-\mathrm{K}^{+}$-ATPase might be involved in the genesis of this phenomenon.

Treatment of rabbit tracheas with S-CMC-Lys significantly reduced the rate of decline of Isc with the greatest effect seen after the mucosal treatment, showing the ability of the mucoactive drug to enhance active ion transport across an airway epithelium. In parallel, S-CMC-Lys significantly lowered R. In this regard, it is important to underline that the fall in $\mathrm{Vms}$ was not modified by S-CMC-Lys, suggesting that the reduction observed for $\mathrm{R}$ after exposure to the drug cannot be attributed to a nonspecific increase in paracellular permeability to ions. Data obtained with amiloride and DPC support this hypothesis, showing that an interference with the ion channel activity can indeed affect total tissue resistance.

As far as the contribution of specific ion transport is concerned, the bioelectric variables of rabbit tracheal epithelium in basal conditions are maintained mainly by active absorption of $\mathrm{Na}^{+}$from the mucosal to the submucosal side [1]. On the other hand, an electrogenic secretion of $\mathrm{Cl}^{-}$anions, contributing to the genesis of the 
potential difference, can also be demonstrated in conditions that limit $\mathrm{Na}^{+}$entry into the epithelial cell [6]. Our data, showing that amiloride decreases Isc by about $30-40 \%$, are only partially in agreement with those reported by Boucher and GATZY [6], who, measuring unidirectional ${ }^{22} \mathrm{Na}^{+}$flux, estimated $\mathrm{Na}^{+}$absorption to account for about $70 \%$ of basal Isc. We did not measure ion fluxes directly in our experiments; however, the method used to calculate the percentage decrease in Isc due to amiloride (peak effect) and DPC is likely to give an accurate estimate of the \% Isc attributable to $\mathrm{Na}^{+}$and $\mathrm{Cl}^{-}$transport, respectively. Moreover, even if $\mathrm{Cl}^{-}$channel-blockers, such as DPC, might be less specific in whole tissue as compared to single channel studies [18], data obtained with bumetanide support the conclusion that the DPC-inhibited fraction of Isc can be attributed to blockade of apical $\mathrm{Cl}^{-}$channels. In fact, in the presence of the $\mathrm{Cl}^{-}$-cation co-transport inhibitor, which reduces basolateral $\mathrm{Cl}^{-}$influx, the effect of DPC on Isc was almost abolished. In summary, our results indicate that the decrease in Isc with time depends on an overall reduction in $\mathrm{Cl}^{-}$flux, which is not due to a specific closure of apical $\mathrm{Cl}^{-}$channels.

As far as the effect of S-CMC-Lys is concerned, data obtained from the ion transport analysis indicate that the protection from Isc fall brought about by the mucoactive drug can be attributed to a specific support of transepithelial $\mathrm{Cl}^{-}$movement. The fact that in the presence of bumetanide S-CMC-Lys could no longer increase either total Isc, and the DPC-inhibited fraction of Isc supports this view. Our data also suggest that the ability of SCMC-Lys to increase $\mathrm{Cl}^{-}$transport might depend on the opening of specific $\mathrm{Cl}^{-}$channels (DPC-inhibited apical channels), since a significant decrease in $\mathrm{R}$ paralleled the recovery of Isc. Since $\mathrm{Cl}^{-}$secretion is coupled to increased water flow into the airway lumen [16], this effect would make mucus more fluid and, if mucus was too solid, would accelerate mucus clearance by cilia and coughing. The capacity of S-CMC-Lys to promote $\mathrm{Cl}^{-}$secretion also gains particular relevance considering that a defect in the regulation of apical $\mathrm{Cl}^{-}$channels is the underlying cause of cystic fibrosis [19], a disease characterized by accumulation into the airways of thick, dehydrated mucous secretion and impaired mucociliary clearance.

The molecular mechanism by which S-CMC-Lys modulates $\mathrm{Cl}^{-}$secretion is not known at the present. The effect of mucosal treatment might depend on a direct action of the compound on the apical conductive $\mathrm{Cl}^{-}$ channels; a similar hypothesis might also apply to the effect observed after submucosal exposure to S-CMCLys, since preliminary pharmacokinetic data revealed the presence of radioactivity associated with the airway surface after oral administration of ${ }^{14} \mathrm{C}$-labelled S-CMC-Lys in rats (Ferrari $\mathrm{M}$, personal communication). On the other hand, it is possible to speculate that S-CMC-Lys might act on both sides of the epithelium via a second mediator or intracellular messenger. In this regard, we are currently investigating the capacity of the mucoactive drug to activate cyclic adenosine monophosphate (cAMP)-dependent protein kinase which, together with protein kinase $\mathrm{C}$ or intracellular $\mathrm{Ca}^{2+}$, is one of the major second messenger pathways involved in the stimulation of $\mathrm{Cl}^{-}$secretion [20, 21].

In summary, the capacity of S-CMC-Lys to support active $\mathrm{Cl}^{-}$transport across an airway epithelium adds more insight into the possible mechanism of its mucoregulatory action. S-CMC-Lys does not possess a direct mucolytic activity [22], whilst, an interference on the balance between fuco- and sialo-mucins has been reported [10] and proposed to be the relevant mechanism involved in the normalization of the secretory function of the bronchial mucosa. The present data suggest that modulation of transepithelial ion transport provided by S-CMC-Lys might also contribute to the regulation of water content of the mucous layer, thereby improving excretion of mucus.

\section{References}

1. Widdicombe JH. Ion transport by airway epithelia. In: Crystal RG, West JB, eds. The Lung: Scientific Foundation. New York, Raven Press Ltd, 1991; pp. 263 271.

2. Marin MG, Zaramba MM. Interdependence of $\mathrm{Na}^{+}$and $\mathrm{Cl}^{-}$transport in dog tracheal epithelium. J Appl Physiol: Respirat Environ Exercise Physiol 1979; 47: 598-603.

3. Widdicombe JH, Welsh MJ. Ion transport by dog tracheal epithelium. Fed Proc 1980; 39: 3062-3066.

4. Boucher RC, Stutts MJ, Gatzy JT. Regional differences in canine airway epithelial ion transport. $J$ Appl Physiol: Respirat Environ Exercise Physiol 1981; 51: 706-714.

5. Jeffery PK, Reid L. Ultrastructure of airway epithelium and submucosal gland during development. In: Hodson WA, ed. Development of the Lung. New York, Dekker, 1977; vol. 6: pp. 87-134.

6. Boucher RC, Gatzy JT. Characteristics of sodium transport by excised rabbit trachea. J Appl Physiol: Respirat Environ Exercise Physiol 1983; 55: 1877-1883

7. Jarnigan F, Davis JD, Bromberg PA, Gatzy JT, Boucher RC. Bioelectric properties and ion transport of excised rabbit trachea. J Appl Physiol: Respirat Environ Exercise Physiol 1983; 55: 1884-1892.

8. Braga PC, Allegra L, Rampoldi C, Ornaghi A, Beghi G. Long-lasting effect on rheology and clearance of bronchial mucus after short-term administration of high doses of carbocysteine-lysine to patients with chronic bronchitis. Respiration 1990; 57: 353-358.

9. Puchelle E, Aug F, Polu JM. Effect of the mucoregulator S-carboxymethylcysteine in patients with chronic bronchitis. Eur J Clin Pharmacol 1978; 14: 177-184.

10. Havez R, Degand P, Roussel P, Rancloux A. Mode d'action biochimique des dèrivès de la cysteine sur le mucus bronchique. Poumon Coeur 1970; 26: 81-90.

11. Widdicombe JH, Nathanson IT, Highland E. Effect of loop diuretics on ion transport by dog tracheal epithelium. Am J Physiol 1983, 245: C388-C396.

12. Al-Bazzaz FJ, Zevin R. Ion transport and metabolic effect of amiloride in canine tracheal mucosa. Lung 1984; 162: 357-367.

13. DiStefano A, Wittner M, Schlatter E, Lang HJ, Englert H, Greger R. Diphenylamine-2-carboxylate, a blocker of the $\mathrm{Cl}^{-}$conductive pathway in $\mathrm{Cl}^{-}$transporting epithelia. Pflugers Arch 1985; 450: S95-S100.

14. Lindman HR. Higher-way models. In: Lindman HR, ed. Analysis of Variance in Experimental Design. SpringerVerlag, 1992; pp. 196-198. 
15. Welsh MJ. Electrolyte transport by airway epithelia. Physiol Rev 1987; 67: 1143-1184.

16. Welsh M, Widdicombe J, Nadel J. Fluid transport across the canine tracheal epithelium. J Appl Physiol: Respirat Environ Exercise Physiol 1980; 49: 905-909.

17. Nathanson I, Widdicombe J, Nadel J. Effect of amphotericin B on ion and fluid movement across dog tracheal epithelium. J Appl Physiol: Respirat Environ Exercise Physiol 1983; 55: 1257-1261.

18. Cabantchik ZI, Greger R. Chemical probes for anion transporters of mammalian cell membranes. Am J Physiol 1992; 262: C803-C827.

19. Widdicombe J, Welsh M, Finkbeiner W. Cystic fibro- sis decreases the apical membrane chloride permeability of monolayers cultured from cells of tracheal epithelium. Proc Natl Acad Sci USA 1985; 82: 6167-6171.

20. Smith P, Welsh M, Stoff J, Frizzell R. Chloride secretion by canine tracheal epithelium. I. Role of intracellular cAMP levels. J Memb Biol 1982; 70: 215-226.

21. Barthlerson RA, Jacoby DB, Widdicombe JH. Regulation of chloride secretion in dog tracheal epithelium by protein kinase C. Am J Physiol 1987; 253: C802-C808.

22. Martin R, Litt M, Mariott C. The effect of mucolytic agents on the rheologic and transport properties of canine tracheal mucus. Am Rev Respir Dis 1980; 121: 495500 . 